\title{
PATERNIDADE, MATERNIDADE E \\ CIDADANIA: questões atuais no quadro canadense
}

\author{
Marie-Blanche Tahon*
}

\begin{abstract}
Resumo: A maternidade e a paternidade não mantiveram uma relação similar em referência à cidadania, aqui compreendida como o exercício de direitos políticos e civis. Na primeira parte do texto, ilustrarei, baseando-me no exemplo da França, como a construção da maternidade serviu para manter as mulheres distantes da cidadania. Com a legalização da contracepção e do aborto, esse tempo acabou. As mulheres se tornaram indivíduos e cidadãs, o que permitiu demandar leis instaurando a paridade. Paralelamente, a igualdade política dos sexos, exprimindo a paridade, colocou a reivindicação da igualdade das sexualidades, tanto no casamento, quanto na parentalidade e no parentesco. O exemplo de Quebec será utilizado para ilustrar quanto o "direito ao filho", como um direito da pessoa, recolocou, com novo vigor, a questão da igualdade entre os sexos. Tudo isso indica quanto a relação entre paternidade, maternidade e cidadania permanece uma questão atual.
\end{abstract}

Palavras-chave: cidadania, direitos civis, direitos políticos, paternidade, maternidade, igualdade, sexualidades.

\section{Mulheres e cidadania}

Como lembra Yan Thomas (1991), em Roma, o pai e o cidadão são um só: um e outro era definido por sua capacidade de falar e de agir em nome de um terceiro. Em contraponto, a mãe era tida como

\footnotetext{
Socióloga, professora na Universidade de Otawa, Canadá, titular da cadeira: "Família e política na teoria sociológica".

Tradução de Ana Liési Thurler do original Paternité, maternité et citoyenneté, produzido para integrar este Dossiê.
}

Artigo recebido em 30 abr. 2006 e aprovado em 27 nov. 2006. 
"o começo e o fim de sua própria família". Em Atenas, um cidadão era o filho de um pai cidadão e de uma mãe filha de um cidadão. Era, portanto, neto de dois avós cidadãos. As mulheres não podiam ser cidadãs - o termo "a ateniense" não existia na língua grega ${ }^{1}$-, pois elas eram tidas como preferindo a criança à cidade, enquanto o cidadão era tido como tendo um amor incomensurável pela cidade (Loraux, 1981, 1989, 1990). A Antiguidade da qual somos herdeiras e herdeiros estabeleceu, portanto, um liame direto entre cidadania e filiação. Ela se caracterizaria, igualmente, por distanciar as mulheres da cidadania.

Notadamente, sob a influência de o Contrato social, de Rousseau, a modernidade democrática inovou, desligando paternidade e cidadania, graças ao princípio de que "todos os homens nascem livres e iguais em direitos". Pais e filhos mais velhos - "irmãos" no espaço político - são iguais em cidadania. Por muito tempo, quase durante dois séculos, as mulheres permaneceram excluídas. Como explicar esse fato, em contradição com o princípio fundamental da democracia moderna? Sustento não terem sido as mulheres, mas as mães que foram mantidas distantes da cidadania moderna. Apesar de Rousseau, a modernidade democrática ainda mantém um liame entre cidadania e filiação, mas esse vínculo é parcial. Ele diz respeito somente a uma categoria do povo: às mulheres, cujo destino é serem mães.

Essa proposição - não foram as mulheres, mas as mães que foram mantidas excluídas da cidadania - pode ser sustentada, atentando-se ao que se passou durante a Revolução Francesa. Levando-se em conta o prosseguimento da História, podemos afirmar: as mulheres são, atualmente, cidadãs como os homens. Não todas: somente aquelas que tenham superado sua exclusão tornandose homens. A democracia moderna é exclusiva, mas não excludente (Fraisse, 2001). Os menores, assim como os estrangeiros, não são cidadãos. Todavia, quando um menor atinge a maioridade, em uma idade estabelecida pela lei, ele acede à cidadania. O mesmo ocorre com o estrangeiro que preencha as condições estabelecidas 
pela lei, para tornar-se um nacional. Do mesmo modo, teria sido esperado das mulheres que elas se tornassem homens para serem reconhecidas como cidadãs, no mesmo patamar que eles. Isso não ocorreu. $\mathrm{O}$ que se produziu nas democracias ocidentais - e tomo o exemplo da França que tem propensão de legislar minuciosamente - foi o fato de as mulheres acederem à cidadania, como os homens, quando se tornou representável a desassimilação da mulher à mãe. Ou seja, quando a lei lhe reconheceu o direito de controlar ela mesma sua fecundidade, legalizando a contracepção (1967) e despenalizando o aborto (1975). No limite, foi o que possibilitou formular a reivindicação da paridade política.

Retornemos ao momento da Revolução Francesa, período em que as mulheres não tinham direitos políticos, mas, singularmente, direitos civis na instituição familiar. Com efeito, a legislação revolucionária promulgou, em 1791 e 1792, a igualdade dos filhos e filhas à herança, a igualdade entre esposo e esposa diante do divórcio por consentimento mútuo - o casamento civil, sendo um contrato, pode ser rompido - e substituiu o pátrio poder pela autoridade parental. Essa legislação teve vida curta, pois o Código Napoleônico de 1804 se apressou em modificá-la profundamente, ainda que mantendo o casamento civil e, oficialmente, a norma da igualdade dos filhos diante da herança (facilmente infringida. Ver, por exemplo, Bourdieu, 2002).

Esse breve espaço de tempo (de 1791-1792 a 1804) nos permite compreender a disjunção, para as mulheres, entre direitos políticos e direitos civis. A vontade dos legisladores revolucionários em promover a igualdade e a liberdade se dirige à família e as mulheres se beneficiam disso. Do mesmo modo, as crianças: a partir daí os pais teriam também deveres em relação a elas (autoridade) e não somente direitos sobre elas (poder). É o nascimento da "família moderna", que não é mais uma "família patriarcal". Sabemos que essa "revolução" da instituição familiar acontece lado a lado com a negação de direitos políticos às mulheres. O questionamento a ser desenvolvido se situa nesse espaço paradoxal. 
Freqüentemente, esse descompasso não é percebido ou é mesmo apagado pelos pesquisadores. Por exemplo, Pierre Rosanvallon escreveu em Le sacre du citoyen (1992, p. 145) :

A proteção rigorosa da esfera privada, que está no coração dos direitos humanos, levou a confirmar mecanicamente e, às vezes mesmo a acentuar, a relegação da mulher à domus. A exclusão das mulheres, paradoxalmente, tem uma certa dimensão liberal e inscreveu na divisão dos sexos o princípio da limitação da esfera política. Inscrição sentida como útil, pois, durante a Revolução, tudo concorria, permanentemente, para a ampliação do campo político. O confinamento da mulher ao espaço doméstico foi percebido como uma das formas e das condições para estabelecer separação clara entre o privado e o público. É igualmente por essa razão que a mulher é privada de direitos políticos durante a Revolução: a visão sociológica tradicional da família e a ideologia liberal da limitação do político então se aliam para apresentar um motivo suplementar da exclusão das mulheres da cidade.

Pretender que, "durante a Revolução", "a visão sociológica tradicional da família" sofreu danos, significa alinhar-se ao que Bourdieu (1998, p. 90) designa um "trabalho histórico de deshistorização", pois esse período está marcado por transformações nas regras que enquadram a instituição familiar (herança, casamento, divórcio, autoridade parental). Isso se tornou possível pelo amálgama entre "espaço doméstico" e "esfera privada", com fortes conseqüências para a compreensão do estatuto das mulheres em relação à cidadania. Assim, para justificar a concessão do direito ao voto e à elegibilidade das mulheres em 1944, Rosanvallon (1992, p. 415) argumentou: "para que o direito ao voto das mulheres seja aceitável ao imaginário democrático" é necessário que "a esposa deixe de se confundir com a criada". Ora, o pós-guerra foi o período em que, mais intensamente, as esposas realizaram trabalhos domésticos gratuitos para seus maridos e filhos. Período em que elas estiveram particularmente confinadas ao espaço doméstico (Friedan, 1966). É importante distinguir privado e doméstico para pensar a relação das mulheres com a cidadania. Amalgamá-los torna-se útil para justificar histórica e politicamente a exclusão das mulheres. 
Retomemos o fio da História. No período da Revolução, as mulheres francesas não tinham direitos políticos - menos por serem mulheres, mais porque a "mãe republicana" é boa figura a ser construída para representar a cidadania. Para articular "igualdade" e "liberdade", foi feito um apelo à "fraternidade". No espaço político, os homens - livres e iguais - são irmãos. Como tornar representável a fraternidade, se o espaço político é o lugar do conflito? A mãe detentora de direitos civis - é chamada a fazer de seus filhos "bons" cidadãos, cidadãos-irmãos. Ela somente poderia cumprir sua missão estando fora do espaço político, privada de seus direitos políticos.

A mãe "republicana" desaparece com o Código Civil (1804), que privou a mulher casada de seus direitos civis. Se - como seus irmãos - ela permanece herdeira, ela não administra sua herança. $\mathrm{O}$ pátrio poder está sintonizado com o poder marital. É abolido o divórcio por consentimento mútuo. Se o divórcio por engano é mantido até 1816, o adultério da esposa - passível de prisão - é, claramente, muito mais reprimido do que o adultério do marido. Podemos arriscar-nos a considerar que a esposa é construída como a filha mais velha de seu marido. É o que ilustra a relação de anterioridade masculina que caracteriza a "valência diferencial dos sexos": "a anterioridade equivale à superioridade e à autoridade, conforme o princípio da diferença das gerações e não sobre o simples modelo da complementaridade" (Héritier, 2002a, p. 17).

Não obstante, o século XIX é marcado pelo desenvolvimento da revolução industial que demanda mão-de-obra operária. Contrariamente aos camponeses no Antigo Regime, para os proletários, o patrão não é mais o pai ou o marido - o que constitui uma fissura nesse edifício. Essa fissura será parcialmente fechada no final do século, com a entrada em cena do modelo "mãe-donade-casa / pai-provedor", marcando o desenvolvimento do espaço doméstico, desconhecido dos operários (Sohn, 1996). Nesse espaço doméstico em emergência, as mães - privadas de direitos políticos e civis - são chamadas a desempenhar um papel "social": a elas cabe produzir crianças com boa saúde e suficientemente polidas para freqüentar a escola primária, tornada obrigatória. Esse período, 
que se prolongou, culminando nos anos 1950-1960, foi propício a se preservar a confusão conceitual entre "privado" e "doméstico": mesmo se elas tinham o direito de votar e de serem votadas, as esposas permanecem submissas ao marido no plano dos direitos civis e isoladas no espaço doméstico. (Na França a taxa de atividade profissional das mulheres atingiu seu mínimo histórico em 1961. Só em 1988 foi retomado o nível de 1911. Ver Théry, 1998, p. 20.)

Os "Trinta Gloriosos" - os anos do pós Segunda Guerra Mundial, marcados pela prosperidade econômica - favoreceram uma primeira "democratização" da educação, que incluiu as jovens. Em torno de 1965, quando o Estado providência se desdobrou em "serviços" (saúde e educação) e a sociedade do consumo se instalou, as mulheres puderam aceder a postos de trabalho. Somente em 1966 o marido deixou de ser autorizado a se opor a que sua mulher tivesse um emprego. ${ }^{2}$ Com a "crise" que sucedeu aos "Trinta Gloriosos", o salário feminino tornou-se menos e menos um salário complementar. A regra passou a ser a tendência de famílias com dois ingressos (desiguais). Como sabemos, o fim dos anos sessenta é marcado pelos ventos da contestação. Estudantes e trabalhadores foram amplamente deixados à margem dos movimentos "revolucionários", que continuavam a fazer da desigualdade entre mulheres e homens uma "contradição secundária". Está aí uma das razões que explicam o desenvolvimento de um novo movimento feminista.

Muito rapidamente esse movimento reivindica a liberalização da contracepção (Lei Newrith, de 1967, cujos interditos à aplicação só caíram em 1972, após a partida de De Gaulle) e a descriminalização do aborto, assim como a repressão ao estupro. Espalharam-se as palavras de ordem: "meu corpo me pertence", "um filho se eu quiser, quando eu quiser", significando sobretudo "nenhuma criança se eu não quiser, quando eu não quiser". Esses anos registram as maiores transformações legislativas: 1970, o estabelecimento da autoridade parental, substituindo o pátrio poder; 1972, igualdade entre filhos adulterinos e legítimos; em janeiro de 1975, aprovação da lei descriminalizando o aborto; em setembro de 1975, aprovação do divórcio por consentimento mútuo. Somente em 
1985, entretanto, uma profunda reforma do Código Civil estabeleceu plenamente a igualdade entre marido e mulher, no interior da família.

Mesmo sem ter sido aplicada imediatamente, podemos celebrar a lei liberalizante da contracepção como elemento deflagrador da eliminação da desigualdade entre mulheres e homens, na lei. Com a liberalização da contracepção e, a seguir, a descriminalização do aborto, é encontrada a "alavanca" (Héritier, 1996) para questionar e superar a dominação masculina. É necessário insistir sobre a importância da lei. Não somente o acesso facilitado à contracepção feminina e o aborto seguro foram importantes. Sobretudo o fato de a lei, desde então, tornar representável a mulher poder dizer "eu", como um ser dotado de razão e consciência e que, em última instância, toma a decisão de consentir ou não com o nascimento de uma criança. Ou seja, assistimos à desassimilação secular entre mulher e mãe. A maternidade não é mais um destino, mas decorre do exercício da vontade de uma mulher. E a lei reconheceu isso.

A associação da maternidade com a vontade coloca fim à representação de que as mulheres estariam irremediavelmente submetidas às "determinações de seu sexo". Tais determinações deixam de ser marcantes, se a maternidade pode decorrer da vontade. Torna-se, então, efetivamente possível considerar a igualdade política entre mulheres e homens. Se as mulheres não são mais definíveis pelas determinações de seu sexo, o estado civil ${ }^{3}$ continua a distinguir duas categorias sexuadas (e somente duas). Duas categorias que têm igual importância. O estado civil é, então, o fundamento racional da reivindicação por paridade: a população está dividida em duas categorias. É lógico que sejam igualmente representadas. Podemos lamentar que, com raras exceções (Kriegel, 1998), essa argumentação não foi usada em proveito de uma nova variante da eterna querela francesa opondo "igualdade" e "diferença" ou "universalismo" e "essencialismo" - reenviando inexoravelmente à naturalização.

Sem retomar uma análise do debate francês em torno da paridade (Tahon, 1998, 1999a, 2000a, 2000b, 2002), não podemos 
deixar de destacar que seu desenrolar foi recuperado no debate em torno da reivindicação pelo Pacto Civil de Solidariedade - PaCS (Fassin e Feher, 1999; Scott, 2005). Para abordar a articulação da igualdade dos sexos - demandando a paridade - e a igualdade das sexualidades - demandando o casamento homossexual - nos deslocaremos da França ao Quebec, onde a questão recebeu uma resposta mais avançada (mesmo com o debate sobre a paridade sendo pouco presente no Quebec).

\section{Maternidade e igualdade das sexualidades}

A situação que prevalece no Quebec e no Canadá é incomparável à situação da França com o PaCS, pois, desde 1999, no Quebec, e em 2000, no Canadá, uma lei permite a casais do mesmo sexo usufruirem os mesmos direitos sociais garantidos aos heterossexuais. Essa lei tem o mérito de situar a reivindicação do casamento homossexual pelo que é: a possibilidade, para os casais do mesmo sexo, de aceder à ordem simbólica vigente para os casais de sexo diferente. $\mathrm{O}$ casamento de casais do mesmo sexo é legal no Canadá desde julho de 2005. A redefinição do casamento - "união de duas pessoas" - é de competência federal. Sem competência para redefinir o casamento, o Quebec instituiu, em 2002, a união civil, que se distingue do casamento somente em dois pontos. Primeiro: para contrato da união civil é necessário ter 18 anos, enquanto é suficiente ter 16 anos para o casamento. Uma segunda diferença reside no fato de que a ruptura de um contrato de união civil - se o casal não tiver filhos - é feita junto ao Notário, ao Cartório e, em idênticas condições, um casal casado deve homologar seu divórcio com um Juiz.

Prevista inicialmente para casais do mesmo sexo, a união civil foi quase instantaneamente aberta a casais de sexo diferente, com demanda de representantes da comunidade $^{4}$ gay e lésbica, ouvidos pela Comissão das Instituições, em fevereiro de 2002. Essa transformação foi reivindicada e aceita pelo Ministro da Justiça e pelos deputados com a intenção de não estabelecer uma instituição 
específica para os homossexuais, para não criar uma "igualdade separada". É, também, em nome da recusa em estabelecer uma "igualdade separada" entre homossexuais e heterossexuais que o Primeiro Ministro do Canadá defendeu, em 2005, o estabelecimento do "casamento civil" e não da união civil a todo o país, como propunham os opositores da redefinição do casamento.

A maior inovação aportada pela união civil do Quebec - sendo de competência provincial, não colocou em questão a instauração do casamento civil - reside no estabelecimento de "novas regras de filiação". A adoção nacional é permitida aos casais do mesmo sexo. É bom lembrar que a adoção nacional é pouco difundida em Quebec, pois poucas crianças são abandonadas e, no país, só é admitida a adoção plena que anula toda filiação anterior. A adoção internacional - forma mais praticada em Quebec - deve se submeter às condições estabelecidas pelos Estados doadores. Entre esses países, a China é o primeiro e exige que o casal adotante seja casado. É improvável que ela rapidamente venha a aceitar a redefinição canadense do casamento. A seguir está o Haiti, que aceita somente mulheres como adotantes. Em outras palavras, as possibilidades de um casal gay ou de um homem só se tornarem pais, via adoção, são mínimas.

Longe de corrigir essa situação, a Lei 84 a reforça. Ela permite que uma criança seja declarada, no estado civil, filho ou filha de duas mães, embora o recurso à mãe portadora seja expressamente interditado, ${ }^{6}$ o que impede que uma criança seja declarada filha ou filho de dois pais. Essa medida foi tomada com a aprovação dos representantes da comunidade gay e lésbica. A co-maternidade é possível pelo recurso à procriação assistida. Ministro e deputados dedicaram a maior parte de seu tempo de deliberação sobre esse projeto de lei para determinar se seria necessário fazer referência à "procriação medicamente assistida" ou à "procriação assistida". Finalmente, optaram por dispensar a expressão "medicamente". Assim fizeram para facilitar, ao máximo, o "projeto parental" de duas lésbicas, como demandaram os representantes da comunidade gay e lésbica, em particular representantes delas. 
Ministro da Justiça e deputados manifestarem ignorar a distinção entre parentalidade (papéis parentais desempenhados pelos adultos, junto aos filhos: alimentá-los, cuidá-los, educá-los) e parentesco (lugar dos pais em uma estrutura de parentesco). ${ }^{7}$ Muitos - porta-vozes e "simples cidadãos" - destacaram as dificuldades práticas encontradas pela companheira da mãe em reuniões de pais na escola, em chegar a uma emergência de hospital ou para passar em uma fronteira. Segundo a porta-voz de uma associação, nove crianças em dez, vivendo com a mãe e sua companheira, estariam nessa situação. Contudo, ela mesma e outros mais pleiteiam maiores facilidades de acesso ao recurso de procriação assistida que, dizem esses demandantes, se difundiu na comunidade. A lei lhes atendeu, esquecendo dificuldades sofridas pelas "madrastas" de nove em dez crianças vivendo em homofamília recomposta.

Graças à legalização da procriação assistida, as clínicas de fertilidade de Quebec não podem mais recusar uma inseminação com doador a uma lésbica casada, nem a uma mulher só. Enfim, uma lésbica casada ou uma mulher só podem fazer um apelo a um "velho amigo", ${ }^{8}$ bastante generoso para the dar esperma recolhido em um recipiente. Nesse caso, mesmo sendo conhecido da futura mãe e não um anônimo, ele nunca poderá reivindicar o título de pai. $\mathrm{O}$ genitor suscetível de pedir esse título - e até um ano após o nascimento da criança - é aquele que deu seu esperma em uma relação sexual (Art. 538.2 do Código Civil de Quebec).

Retornemos ao "projeto parental”. Não sendo definido em lei, nada há a ser registrado, como acontece, por exemplo, na França, para os casais heterossexuais que recorrem à inseminação artificial. Antes da intervenção de um terceiro doador, os futuros pai e mãe dão seu consentimento diante de um juiz ou de um notário que lhes informa das conseqüências de seu gesto, em relação à filiação (Art. 311-20 do Código Civil francês). Em Quebec, o "projeto parental" é estritamente privado, mas implica a "presunção da maternidade" da cônjuge da mãe biológica, como disseram deputados e Ministro. Em caso de ruptura, ela pagaria pensão alimentícia à criança. Aliás, o acesso de uma mulher só a um "projeto parental", como não 
definido, consagra um direito individual à procriação assistida. $\mathrm{O}$ que pode parecer curioso, se considerarmos que a legalização da co-maternidade repousa sobre a vontade de ratificar "o direito das crianças do Quebec, de todas as crianças do Quebec, a ter dois pais". Essa anomalia não foi percebida pelo legislador. É verdade que aceitar a procriação assistida para uma lésbica em casal e recusá-la para uma mulher só, teria criado entre elas uma "igualdade separada". Contudo, essa explicação é insuficiente, pois uma "igualdade separada", ou mais precisamente uma desigualdade, é efetivamente criada entre homens e mulheres e, também, entre mulheres.

Desigualdade entre homens e mulheres: os primeiros - em casal ou sós - não podem recorrer à procriação assistida. As segundas - em casal ou sós - podem ter acesso a esse recurso. Desigualdade entre mulheres: no Quebec, a mulher que tenha vivido a gravidez e o parto pode pretender o título de mãe, do mesmo modo que uma mulher que não tenha vivido a gravidez e o parto, sob a condição de que ela viva com outra mulher. Sem gravidez e parto, uma mulher que vive com um homem não pode pretender o título de mãe. A solução para corrigir essa desigualdade seria a legalização da mãe portadora, acessível a todos, qualquer que seja seu sexo, orientação sexual e estatuto civil (casamento, união civil, união de fato, celibato). A Lei C-6, votada pelo Parlamento canadense em 2004, legalizou o recurso à mãe portadora, sob a condição de não vir a ser remunerada (gravidez e parto como dom altruísta, à semelhança ao dom do esperma e ao dom do ovócito) e proíbe qualquer discriminação quanto à orientação sexual. Parece não considerar as pessoas sós. Essa Lei, que parece não considerar as pessoas sós, ainda não foi regulamentada. Quando isso ocorrer, ela entrará em contradição com o Código Civil do Quebec que, em seu artigo 541, interdita o recurso à mãe portadora. Não é improvável que, quando tiver que decidir, a Suprema Corte torne a dar precedência à lei federal.

Legalizando a co-maternidade, a lei do Quebec tem, como conseqüência, a criação de duas categorias de crianças: aquelas que são declaradas filhos ou filhas de um pai e de uma mãe e aquelas que são declaradas filhas de duas mães. Ou seja, é às crianças 
que cabe tornar público, em seu registro de nascimento, a orientação sexual de seus pais. Essa conseqüência passou despercebida ao legislador que, sensível ao caráter estigmatizante que revestia a união civil se reservada somente aos homossexuais, tornou-a universal, acessível a todos, independente da orientação sexual dos cônjuges.

A noção de "igualdade separada", como vimos, não chegou a nivelar todas as situações criadas pelo reconhecimento do casamento como um direito da pessoa, quando a aliança continua a presidir a filiação. É verdade que a redefinição do casamento - união de duas pessoas - foi admitida pela maioria dos parlamentares federais, diante do argumento de que o fundamento do casamento é o amor entre os cônjuges, não entrando em questão a orientação sexual. Defensores argumentam reiteradamente que a procriação não deveria ser levada em consideração para legalizar o casamento de casais do mesmo sexo, pois o casamento heterossexual era permitido às mulheres que passaram da idade reprodutiva. De todo modo, não está no âmbito federal legislar em matéria de filiação - matéria de competência provincial. Em Quebec, as "novas regras de filiação", instauradas com a aprovação da lei instituindo a união civil, criaram desigualdade entre gays e lésbicas e entre lésbicas e heterossexuais. Essas regras criaram duas categorias de crianças, imputando-lhes a responsabilidade de publicizar a orientação sexual de seus pais.

\section{Maternidade e cidadania}

O exemplo de Quebec ilustra quanto a articulação da igualdade dos sexos e a articulação da igualdade das sexualidades não fica resolvida, quando o direito ao filho, além do casamento, é tido como direito da pessoa - como se diz no Canadá - ou como direitos do homem e do cidadão - como se diz na França. A gestão política da paternidade e da maternidade toca, inevitavelmente, na diferença dos sexos, mais particular e especialmente, na capacidade de as mulheres darem nascimento a crianças de um e outro sexo. A partir do momento em que a lei reconheceu o direito de as mulheres controlarem sua fecundidade, essa capacidade passou a 
ser enquadrada por um arsenal de regras e de leis que asseguram a dominação masculina.

A emergência da reivindicação do homoparentesco - e não da homoparentalidade (Cadoret, 2002, p. 39) — recoloca com novo vigor a maternidade e a paternidade em seus laços com a cidadania. $\mathrm{Na}$ modernidade democrática, a paternidade está desligada da cidadania, pois a relação dos homens cidadãos é fundada sobre a fraternidade, enquanto a maternidade está erigida como obstáculo político ao acesso das mulheres ao exercício da cidadania. Essa articulação entre paternidade e maternidade em face do político é duplicada com a instituição civil do "chefe de família" (Verjus, 2002) e, no século XIX, justificou a manutenção das mulheres longe de todos os direitos. A maternidade deixou de ser um obstáculo ao exercício da cidadania das mulheres, quando a lei legalizou o acesso à contracepção e descriminalizou o aborto, as mulheres não são mais definíveis e marcadas por "determinações de seu sexo". Essa condição - necessária e suficiente para que as mulheres se tornassem cidadãs e pela qual o movimento de libertação das mulheres lutou não depende de uma vontade das feministas para se situar sob a égide do essencialismo, como a censura de Marcela Iacub (2002, 2004) pretende fazê-lo. Ela reabilita o meio utilizado pela República ${ }^{9}$ para justificar sua incoerência em não incluir mulheres no princípio "todos os homens nascem livres e iguais em direitos". Tendo construído a maternidade como um obstáculo ao acesso à cidadania, o regime político republicano chegou a desconstruí-la sobre o mesmo terreno - o que não constitui uma fatalidade, ${ }^{10}$ mas um fato histórico.

A legalização da bi-maternidade, excluindo toda referência à paternidade, em nome do respeito aos direitos da pessoa, funda um novo sistema de parentesco até aqui desconhecido dos antropólogos - o que não constitui razão para desqualificá-lo, pois, como destaca Françoise Héritier (2002b, p. 130), "não podemos dizer que haja alguma exigência, antropologicamente fundada, para a preservação desse estado". Essa inovação depende de uma decisão política. $\mathrm{Na}$ democracia, espera-se por uma medida legislativa que promova a 
igualdade de todos os cidadãos. A legalização da bi-maternidade não está acima de qualquer suspeita.

Outra interrogação diz respeito à possibilidade de uma "nova" apreensão da maternidade, reconciliada com um passado não tão distante, que fazia dela o destino das mulheres. As lutas feministas pela legalização da contracepção e a descriminalização do aborto não visavam eliminar a maternidade da vida das mulheres. Perseguiam o objetivo de romper com a fatalidade e de inscrever seu caráter relativo em sua vida. Essa perspectiva, entretanto, foi recapturada pelo desenvolvimento das novas tecnologias reprodutivas (NTR) que fazem reluzir a possibilidade de suspender a esterilidade. Submetendo as mulheres (Memmi, 2003) a exames e tratamentos médicos durante meses, senão anos, essas tecnologias transformam a fecundação no centro de suas existências.

Sem a difusão das NTR, a reivindicação da bi-maternidade teria sido impensável. Com tal difusão, outro passo é dado, pois ela concerne não a uma, mas a duas mulheres, que se mobilizam para realizar seu desejo comum de um filho, apesar das transformações que as cercam. Por ocasião das audiências da Comissão das Instituições em Quebec, uma porta-voz da comunidade gay e lésbica, figura histórica do feminismo em Quebec, não temeu defender a bimaternidade, enunciando: "o desejo de um filho não é uma escolha". Essa enunciação visava às lésbicas, pois essa militante reiterava a oposição ao recurso às mães portadoras, dando honrarias ao famoso "instinto materno", que tão fortemente pesou para justificar o não acesso das mulheres à cidadania. Freqüentemente, a reverência à maternidade reforça o confinamento das mulheres à dominação, sob suas diversas formas. Seria duvidoso que a aceitação da dupla maternidade - unanimemente admitida pela Assembléia Nacional de Quebec, composta 70\% por deputados - escapasse desse quadro. 


\section{Notas}

1 Como, aliás, também não temos essas flexões no português. Em sua reflexão, a autora se reporta ao francês, idioma em que há as flexões "athénienne" e "athénien" (N. da T.).

2 No Brasil, a Lei 4.121, de 27 de agosto de 1962 - o Estatuto da mulher casada - estabeleceu o direito ao trabalho, à prática de atos de comércio pela mulher casada (N. da T.).

3 A autora se refere ao Cartório e à lavratura do Registro Civil de Nascimento, estabelecendo duas categorias de sexo: masculino e feminino (N. da T.).

4 É a forma como se apresentam.

5 Quando o casamento era reservado a um homem e uma mulher, a lei canadense se contentava em falar em "casamento". Aberto a duas pessoas, tornou-se "casamento civil". Essa nuance foi feita para não pressionar Igrejas que o condenam, a celebrá-lo. No Canadá, como no Quebec, o casamento civil não é anterior ao casamento religioso e o padre ou o pastor é um "oficial do estado civill".

6 O Artigo 541 do Código Civil do Quebec está assim redigido: “Todo acordo pelo qual uma mulher se engaja em procriar e portar uma criança no lugar de outra é nulo, de nulidade absoluta".

7 No francês, "parentalité" e "parenté".

8 Expressão consagrada nas audiências da omissão das instituições e retomada pelo Ministro e por deputados nas discussões para redigir o projeto.

9 Entendida como regime político.

10 Não fica excluída a possibilidade de que Estados, sem ter conhecido o laborioso encaminhamento das repúblicas modernas a partir do século XVIII, não dependam de servir-se dessa via para estabelecer a igualdade política entre os sexos. Pode ser que a instrumentalização da figura da mãe seja uma especificidade "ocidental" (greco-romana-cristã) (ver Tahon, 1999b, 2004). 


\section{Paternité, maternité et citoyenneté: des questions octuelles au Canada}

Resumé: La maternité et la paternité n'ont pas entretenu un rapport similaire à l'égard de la citoyenneté, ici entendue en tant qu'exercice des droits politiques et des droits civils. Dans la première partie du texte, en me basant sur l'exemple de la France, j'illustrerai comment la construction de la maternité a servi à tenir les femmes à distance de la citoyenneté. Cette époque est révolue depuis que sont légalisées la libéralisation de la contraception et la dépénalisation de l'avortement. Les femmes sont alors devenues des individus et dès lors citoyennes. Ce qui a permis, à terme, de revendiquer une loi instaurant la parité. Parallèlement à l'égalité politique des sexes qu'exprime la parité, a été mise de l'avant la revendication de l'égalité des sexualités tant au niveau du mariage que de la parenté. L'exemple du Québec sera alors utilisé pour illustrer comment l'appréhension du "droit à l'enfant" comme un droit de la personne repose, à nouveaux frais, la question de l'égalité des sexes. Ce qui indique combien le rapport entre paternité, maternité et citoyenneté reste une question d'actualité.

Mots-clés: citoyenneté, droits civis et droits politiques, paternité, maternité, egalités, sexualités.

\section{Referências:}

BOURDIEU, Pierre. La domination masculine. Paris: Seuil, Liber, 1998. . Le bal des célibataires. Paris: Seuil, Points, 2002.

CADORET, Anne. Des parents comme les autres: homosexualité et parenté. Paris: Odile Jacob, 2002.

FASSIN, Éric, MICHEL, Feher. Parité et PaCS: Anatomie politique d'un rapport. In : BORRILLO, Daniel; FASSIN, Éric; IACUB, Marcela (dir.). Au-delà du PaCS: l'expertise familiale à l'épreuve de l'homosexualité. Paris: PUF, 1999. p. 13-43

FRAISSE, Geneviève. Les deux gouvernements: la famille et la cité. Paris: Gallimard, Folio, 2001. 
HÉRITIER, Françoise. Masculin/féminin: la pensée de la différence. Paris: Odile Jacob, 1996.

. Masculin/féminin II: dissoudre la hiérarchie. Paris: Odile Jacob, 2002a.

. Anthropologie de la famille. In: Université de tous les savoirs, La Société et les Relations sociales, volume 12, Paris: Odile Jacob Poches, 2002b. p. 113-131.

IACUB, Marcela. Le crime était presque sexuel et autres essais de casuistique juridique. Paris: EPEL, 2002.

. L'empire du ventre: pour une autre histoire de la maternité. Paris: Fayard, 2004.

KRIEGEL, Blandine. Philosophie de la République. Paris: Plon, 1998.

LORAUX, Nicole. Les enfants d'Athéna. Paris: Maspero, 1981.

. Les expériences de Tirésias. Paris: Gallimard, 1989.

. Les mères en deuil. Paris: Seuil, 1990.

MEMMI, Dominique. Faire vivre et laisser mouri: le gouvernement contemporain de la naissance et de la mor. Paris: La Découverte, 2003.

ROSANVALLON, Pierre. Le sacre du citoyen: histoire du suffrage universel en France. Paris: Gallimard, 1992.

SCOTT, Joan W. Parité! L'universel et la différence des sexes. Paris: Albin Michel, 2005.

SOHN, Anne-Marie. Chrysalides: femmes dans la vie privée (XIXe-XXe). Paris: Publications de la Sorbonne, 1996. 2v.

TAHON, Marie-Blanche. La revendication de la démocratie paritaire. Politique et Société, v.17, n.1-2, p. 13-47, 1998.

. Citoyenneté et parité politiques. Société et Sociétés, v. 31, n. 2, p. 73-87, 1999a.

. Femmes et citoyenneté en Algérie. AWAL, n. 20, p. 43-60, $1999 b$.

. La parité n'est pas une revendication féministe. International Journal of Canadian Studies/Revue Internationale d'Études Canadiennes, n. 21, p. 125-140, 2000a. 
TAHON, Marie-Blanche. Citoyenneté et division des sexes. Canadian Journal of Political Science/Revue Canadienne de Science Politique, v. 33, n. 3, p. 443-463, $2000 \mathrm{~b}$.

. La parité en débat au-delà de Versailles. Modern \& Contemporary France, v. 10, n. 1, p. 25-43, 2002.

. 'Mère', 'sœur' et politique: à partir de l'Algérie. In: VEAUVY, Christiane; ROLLINDE, Marguerite; AZZOUG, Mireille (dir.). Les femmes entre violences et stratégies de liberte: Maghreb et Europe $d u$ Sud. Paris: Bouchene, 2004. p. 331-344

THÉRY, Irène. Couple, filiation et parenté aujourd'hui: le droit face aux mutations de la famille et de la vie privée. Paris: Odile Jacob/La Documentation Française, 1998.

THOMAS, Yan. La division des sexes en droit romain. In: DUBY, Georges; PERROT, Michelle (dir.). Histoire des femmes en Occident, tome 1. Paris: Plon, 1991. p. 103-156.

VERJUS, Anne. Le cens de la famille: les femmes et le vote, 1789-1848. Paris: Belin, 2002. 